\title{
Multi-minicore disease: A rare form of myopathy
}

\author{
M. C. Sharma, S. Gulati ${ }^{\star}$, C. Sarkar, D. Jain, V. Kalra*, V. Suri \\ Departments of Pathology and ${ }^{*}$ Pediatrics, All India Institute of Medical Sciences, New Delhi, India
}

\begin{abstract}
Background: Multi-minicore disease is a rare form of myopathy characterized by slowly progressive or nonprogressive muscle weakness and characteristic multiple cores within the muscle fibers. To the best of our knowledge, this is first documentation of the clinicopathological features of this rare entity from India. Materials and Methods: All cases of multi-minicore disease diagnosed in our laboratory were retrieved. Clinical and pathological features were reviewed. Result: During a period of two years (January 2004 to December 2005), we received 985 muscle biopsies for various reasons. Of which, 15 were diagnosed as myopathies and four of which were of multi-minicore disease. Thus, multi-minicore disease comprises $0.40 \%$ of all muscle diseases and $26.6 \%$ of all myopathies. All were male and presented in early childhood (first decade of life) with generalized hypotonia and muscle weakness. All of them had dysmorphic facies and three had high arched palate. CPK levels were normal and EMG was myopathic except in one patient. Microscopic examination revealed minimal changes with Type I fibers' predominance but characteristic multiple cores in the myofibers. Ultrastructural examination showed both structured and unstructured cores. Conclusions: Multi-minicore disease, although a rare form of myopathies, should be suspected in children who present with generalized hypotonia and slowly progressive muscle weakness along with dysmorphic facies.
\end{abstract}

Key words: Central core, core disease, histochemistry, multiminicore disease, myopathy, ultra structure

Multi-minicore disease (MCD) was first described by Engel et $a l^{[1,2]}$ as multicore disease but later reported as minicore disease by Currie et al. ${ }^{\left[{ }^{3]}\right.}$ Pleocore disease, myopathy with multiple mini cores and focal loss of cross striations are descriptive terminologies for the same process. ${ }^{[4-6]}$ It is characterized by sarcomeric disruption and multiple cores on oxidative stains. Nearly 100 cases have been reported, mostly as case reports except two case series..$^{[7,8]}$
We report four cases of MCD because of its rarity and to the best of our knowledge it has not been reported in the Indian literature so far.

\section{Materials and Methods}

\section{Clinical features are summarized in Table 1 Case 1}

This two-year-old male child, a product of nonconsanguineous marriage, was born at full term by lower segment cesarean section for breech presentation. The child was floppy at birth and there was delay in attainment of motor milestones. There was history of difficulty in running and getting up from stairs. Examination showed generalized hypotonia, triangular mouth, long facies with long philtrum and high arched palate. There was no wasting but the muscle power in the lower limbs was $3+$. There was no spinal rigidity. The lower ribs were splayed. Creatine phosphokinase (CPK) level was $31 \mathrm{u} / \mathrm{L}$ (normal level 25-200 u/L). EMG was not done. The disease course was static and his level of function was that of minimal assist. Muscle biopsy was done with a clinical diagnosis of myopathy.

\section{Case 2}

A five-year-old male child presented with history of developmental delay and generalized hypotonia and child was floppy at birth. There was delay in attainment of motor milestones. There was history of difficulty in climbing stairs and getting up from the floor. This child was a product of a nonconsanguineous marriage and born at full term. The mother gave history of decreased fetal movements in the last trimester of pregnancy. Examination revealed myopathic facies and high arched palate. There was weakness of the muscles of the face, neck and back. The muscle power was $3 / 5$ in the upper limbs both proximally as well as distally but in the lower limbs it was $3 / 5$ proximally and $4 / 5$ distally. There was no spinal deformity. The CPK level was $59 \mathrm{u} / \mathrm{L}$ and EMG showed myopathic pattern. The CT scan head showed bilateral frontal lobe atrophy. Muscle biopsy was done with a 


\begin{tabular}{lllcr}
\hline Age/sex & Age of onset & Clinical features & CPK (U/L) & Electromyography \\
2/M & Since birth & Global developmental delay, generalized hypotonia & 31 & Not done \\
5/M & Since birth & Global developmental delay, generalized hypotonia & 59 & Myopathic \\
8/M & 3 years & Frequent fall and difficulty in standing & 109 & Myopathic \\
9/M & Early childhood & Global developmental delay, generalized hypotonia & 44 & Fasciculations \\
\hline
\end{tabular}

${ }^{*} \mathrm{M}$ - Male, CPK-creatine phosphokinase

clinical diagnosis of myopathy. The child had started climbing stairs without support but unfortunately this child succumbed consequent to a fulminant chest infection.

\section{Case 3}

This eight-year-old boy presented with complaints of frequent falls, history of difficulty in running, climbing stairs and getting up from the floor since the age of three years. There was no history of feeding or respiratory difficulties. The antenatal period was unremarkable. Examination showed long facies and high arched palate. The deltoid, supraspinatous, biceps, quadriceps and neck muscles were atrophied whereas the spinal muscles were normal. His muscle power was $4 / 5$ in all the limbs. His level of function was that of complete independence. The EMG was myopathic and the CPK level was $109 \mathrm{u} / \mathrm{L}$. The course of the disease was static.

\section{Case 4}

A nine-year-old boy presented with history of global developmental delay, generalized hypotonia and facial dysmorphism. There was history of difficulty in standing from sitting position, climbing stairs and running. He also had difficulty in drinking and eating. Examination revealed generalized hypotonia, long facies and contractures. Reflexes were diminished. The muscle power was $2 / 5$ in the upper limbs proximally and $3 / 5$ distally whereas in the lower limbs it was $2 / 5$ proximally and $4 / 5$ distally. The EMG revealed fasciculations and the CPK level was $44 \mathrm{u} / \mathrm{L}$. Muscle biopsy was done with a clinical diagnosis of spinal muscular atrophy. Genetic studies for SMA gene revealed no exon 7 deletions. He was gaining motor milestones gradually. None of our patients had ptosis, external ophthalmoplegia or hand muscle weakness.

In all patients muscle biopsy specimens were taken from the vastus lateralis of the left quadriceps. Each biopsy was received in fresh state without any fixative or additive and was divided into three pieces. One piece was fixed in $10 \%$ neutral buffered formalin, which was routinely processed and paraffin-embedded. Five-micron thick sections were cut and hematoxylin and eosin-stained. The second piece was fixed in $2.5 \%$ glutaraldehyde in $0.1 \mathrm{M}$ phosphate buffer saline for electron microscopy, post-fixed with $1 \%$ osmic acid and embedded in epoxy resin. Ultrathin sections were double-stained with uranyl acetate and lead citrate and examined under a transmission electron microscope (TEM, Morgagni 268, Holland). The third bigger piece was immediately snap-frozen in isopentane precooled in liquid nitrogen at $80^{\circ} \mathrm{C}$. Six to 8-micron thick cryostat sections were cut and stained with hematoxylin and eosin ( $\mathrm{H}$ and $\mathrm{E}$ ), modified gomori trichrome (MGT), periodic acid Schiff (PAS), oil red O, ATPase at pH 9.6, 4.6 and 4.3 , nicotinamide adenine dinucleotidetetrazolium reductase (NADH-TR), succinic dehydrogenase (SDH) alone as well as combined with cytochrome oxidase (Cox with SDH), myophosphorylase, amylopectinase, phosphofructokinase (PFK) and adenylate deaminase. Immunohistochemical staining was done by streptavidin-biotin immunoperoxidase complex method using antibody against merosin, beta dystroglycan, $\alpha-2$ actinin (dil 1:50) and filamin c (dil 1: 100). These antibodies were procured from M/S Novocastra, UK.

\section{Results}

During a period of two years (January 2004 to Dec 2005), we received 985 muscle biopsies in our department for various reasons. Of which, 15 were diagnosed as myopathies and four of them were diagnosed as MCD. Thus, MCD comprises $0.40 \%$ of all muscle diseases and $26.6 \%$ of all myopathies.

Muscle biopsies in all four patients showed similar changes. Microscopic examination revealed normal fascicular architecture with no endomysial or perimysial fibrosis and adipose tissue infiltration [Figure 1]. There was mild variation in fiber size without central localization of nuclei. Degenerative or regenerative fibers were not seen. There was no evidence of myophagocytosis.

Oxidative stains revealed Type I predominance which was further confirmed by ATPase staining at ph 9.4. Multiple small unstained areas were seen in both Type 1 and 2 fibers on SDH, NADH-TR and COX staining [Figure 2]. These cores were not evident in ATPase stain. These cores were multiple, small in size and were not sharply demarcated. MGT and other stains did not reveal any abnormality. Immunohistochemical staining for merosin and actinin was normal and there was no accumulation of filamin $\mathrm{c}$ in the cores.

\section{Ultrastructural examination}

Electron microscopic examination revealed characteristic unstructured and structured cores in the myofibers. The unstructured cores revealed disruption of the myofibrillary network and destruction of $\mathrm{Z}$ bands as 


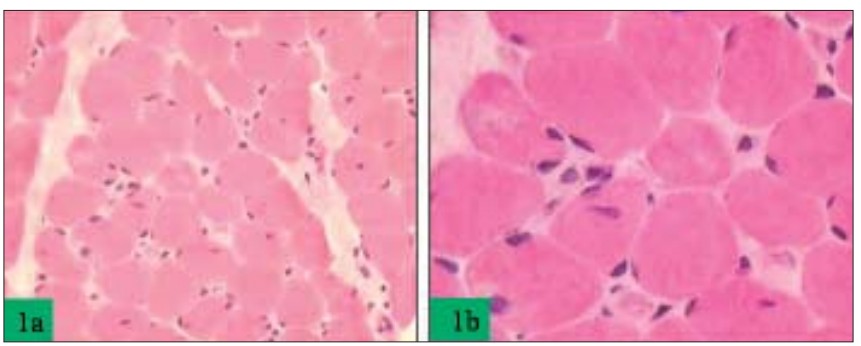

Figure 1AB: Photomicrograph showing minimal variation in fiber size and mild endomysial fibrosis (Case 3: A- H/E, 100x; B- H/E, 200x respectively)

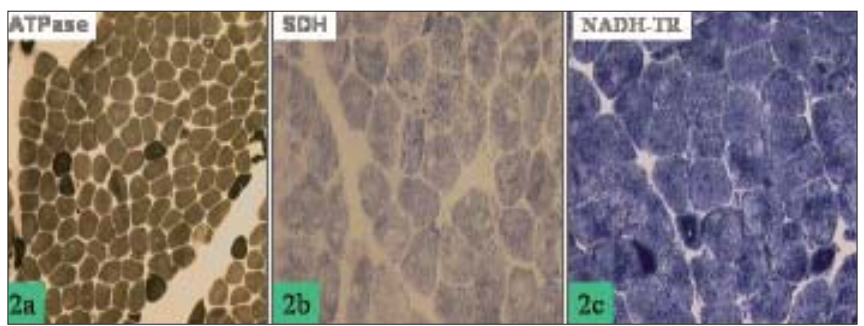

Figure 2 A-C: Photomicrographs of Case 2 showing Type I predominance (A; ATPase $9.4 \times 100)$ and multiple small unstained areas with SDH and NADH-TR stains (B and C; 200x respectively)

compared to structured cores which had streaming of $\mathrm{Z}$ bands [Figure 3]. These cores were depleted of mitochondria. Their number varies from single to multiple cores in a myofiber. Based on the above features the diagnosis of multi-minicore disease was made in all cases.

\section{Discussion}

MCD is a myopathy characterized by the presence of multiple small areas of myofibrillary disorganization and diminished mitochondrial oxidative activity (minicores) in the myofibers. The other differential diagnoses of these cores are central cores of central core disease and target or targetoid fibers seen in the course of reinnervation. In central core disease (CCD) the cores appear as well punched out areas, single or up to three in number, run from sarcomere to sarcomere and are mostly seen in Type 1 fibers. Mostly, cores are central in location but can be eccentric. In contrast, the cores in MCD are not well defined, multiple, small and never extend through the entire length of the muscle fiber and are characteristically seen in both Type 1 and Type 2 fibers. Ultra-structurally, the cores of MCD are similar to the cores of CCD and are characterized by disruption of the myofibrillary network. Both structured and unstructured cores are seen. Like central cores, targets are single, central in location and seen in Type 1 fibers but do not extend the entire length of the fiber. It consists of three concentric zones. The innermost zone displays no mitochondrial, phosphorylase or ATPase activity. The activity is increased in the intermediate zone and is normal in the peripheral zone. The target fibers with normal intermediate zone are
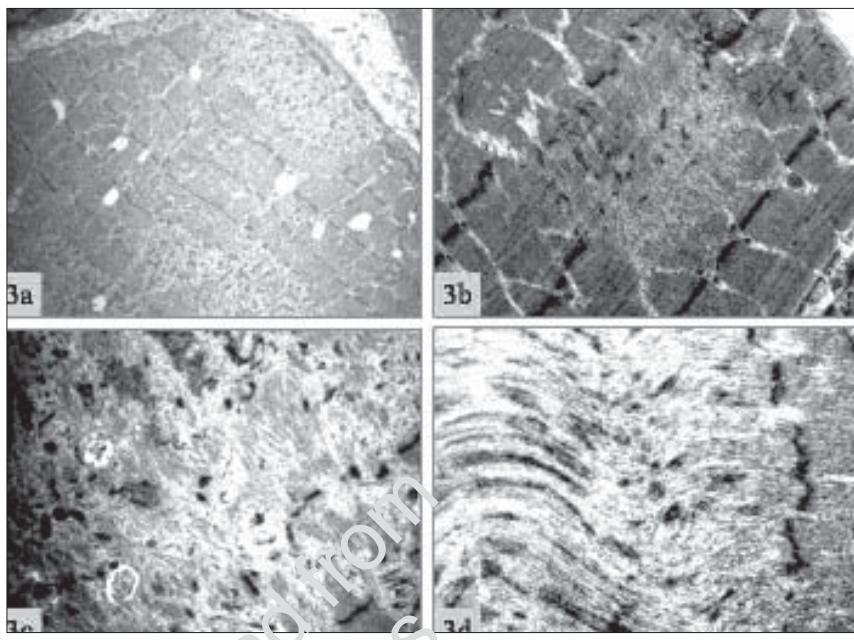

Figure 3: Electron photomicrographs showing structured and unstructured cores (Case 1: 1250x, Case 2: 2250x, Case 3: 6250x and Case 4: $8250 x$ respectively)

known as targetoid fibers.

Although the presence of cores is a prerequisite for the diagnosis of MCD it is not pathognomic of the disease. Minicores have been seen in Mar fan's syndrome, cerebroretino-muscular syndrome, Type III glycogenosis, inflammatory myopathies, emetine myopathy, muscular dystrophies and anhidroectodermal dysplasia. ${ }^{[9,10]}$ Therefore the diagnosis should only be made when minicores are numerous and represent a dominant feature.

The clinical features of MCD are similar to other myopathies. MCD is often sporadic and autosomal recessive in inheritance but rarely can be autosomal dominant. ${ }^{[11]}$ It is characterized by early onset of symptoms which are nonprogressive in nature and usually nonfatal. Onset is usually in infancy or early childhood with hypotonia, delayed motor milestones or waddling gait as also observed in our patients but onset can be as early as in utero characterized by decreased fetal movements, as observed in Case 2 and arthrogryposis. Rarely, onset may be late. Limb weakness is proximal, facial and bulbar weakness in the form of mild ptosis and external ophthalmoplegia is common. The progressive weakness of respiratory muscles, severe scoliosis and rarely, cardiac involvement are the cause of death. Based on the pattern of muscle involvement, Ferreiro et $a{ }^{\left[{ }^{[8]}\right.}$ classified these patients into four categories; the classical form is the most common and is characterized by weakness of axial muscles, severe scoliosis and respiratory muscle involvement. Mild cardiac involvement and facial dysmorphic features can also be seen. The second group was of severe form showing pharyngolaryngeal involvement with lack of head control. The third category had antenatal onset with arthrogryposis whereas the fourth group was of progressive form with hand amyotrophy. All the patients under discussion probably belong to the classical form and the course of the disease was static or they were improving with time as also has been observed 
in the literature. None of our patient had ptosis, bulbar weakness or hand muscle weakness.

Although the morphology of this entity is well defined but is still searching for its genetic boundaries. ${ }^{\left[{ }^{8]}\right.}$ Morphologically it may appear as a single entity but genetically it seems to be a heterogeneous group. Recently, mutations of the selenoprotein $\mathrm{N}$ gene have been described in classical MCD of autosomal recessive form and this locus is identified on Chromosome $1 \mathrm{p} 36 .^{[12,13]}$ The presence of multiple cores has also been reported in rigid spine syndrome. ${ }^{[14]}$ Selenoprotein $\mathrm{N}$ gene mutations are classically described in myopathies with rigid spine disease. Since multi-minicores can also be seen in rigid spine disease both these entities are grouped as SEPNrelated myopathy. ${ }^{[10]}$ Secondly, the presence of minicores in CCD, centronuclear myopathy (CNM) and rod disease (nemaline myopathy) may indicate that it may not be a separate entity ${ }^{[15,16]}$ or may be a transient phase of these myopathies. Moreover, recently, susceptibility to malignant hyperthermia in vitro has also been reported in patients with $\mathrm{MCD}^{[17-19]}$ as well as MCD can be a product of RYR1 mutations. ${ }^{[20]}$ This locus had been identified on Chromosome $19 q^{13.1}$, thus linking the two diseases at a genetic level. Therefore, there is blurring of nosologic boundaries between MCD, CCD, rigid spine disease and selenoprotein N1. Thus, at the moment this entity appears to be heterogeneous both morphologically as well as genetically. These cores are characterized by disruption of the sarcomeric network and show accruing of various muscle proteins like filamin C, RYR1 and SEPN1, thus indicating that this disease is a form of protein aggregating myopathy. ${ }^{[21]}$

This report highlights the importance of enzyme histochemistry and ultrastructural examination in the diagnosis of MCD in the absence of the availability of genetic studies.

\section{References}

1. Engel AG, Gomez MR. Congenital myopathy associated with multifocal degeneration of muscle fibers. Trans Am Neurol Assoc $1966 ; 99: 223$.

2. Engel AG, Gomez MR, Groover RV. Multicore disease. A recently recognized congenital myopathy associated with multifocal degeneration of muscle fibers. Mayo Clin Proc 1971;46:666-81.

3. Currie S, Noronha M, Harriman D. Minicore disease. $3^{\text {rd }}$ International Congress on Muscle Diseases. Excerpta Medica: Amsterdam; 1974. p. 12.

4. Engel WK. Central core disease and focal loss of cross striation. In: Goldenshohn ES, Appel SH, editor. Scientific approaches to clinical neurology. Lea and Febiger: Philadelphia; 1977. p. 1555-71.

5. Ricoy JR, Cabello A, Goizueta G. Myopathy with multiple minicorereport of two siblings. J Neurol Sci 1980;48:81-92.

6. Martin JJ, Bruyland M, Busch HF, Farriaux JP, Krivosic I, Ceuterick C. Pleocore disease. Multi-minicore disease and focal loss of cross striations. Acta Neuropathol [Berl] 1986;72:142-9.

7. Jungbluth H, Sewry C, Brown SC, Manzur AY, Mercuri E, Bushby $\mathrm{K}$, et al. Minicore myopathy in children: A clinical and histopathological study of 19 cases. Neuromuscul Disord 2000;10:264-73.

8. Ferreiro A, Estournet B, Chateau D, Romero NB, Laroche C, Odent $\mathrm{S}$, et al. Multi-minicore disease-searching for boundaries: Phenotype analysis of 38 cases. Ann Neurol 2000;48:745-57.

9. Goebel HH. Multi-mini core disease. In: Karpanti G, editor. Structural and molecular basis of skeletal muscle diseases. ISN Neuropath Press: Basel; 2002. p. 68-9.

10. Kathyrn North. Congenital Myopathies. In: Myology. $3^{\text {rd }}$ ed. Engel AG, Armstrong CF, editors. 2003. p. 1495-502.

11. Paljarvi L, Kalimo H, Lang H, Savontaus ML, Sonninen V. Minicore myopathy with dominant inheritance. J Neurol Sci 1987;77:11-22.

12. Ferreiro A, Quijano-Roy S, Pichereau C, Moghadaszadeh B, Goemans N, Bonnemann C, et al. Mutations of the selenoprotein $\mathrm{N}$ gene, which is implicated in rigid spine muscular dystrophy, cause the classical phenotype of multiminicore disease: Reassessing the nosology of early-onset myopathies. Am J Hum Genet $2002 ; 71: 739-49$

13. Tajsharghi H, Darin N, Tulinius M, Oldfors A. Early onset myopathy with a novel mutation in the Selenoprotein $N$ gene [SEPN1]. Neuromuscul Disord 2005;15:299-302

14. Ben Hamida M, Hentati F, Ben Hamida C. Multiminicore disease in a rigid spine syndrome. Rev Neurol [Paris] 1987;143:284-9.

15. Treves S, Anderson AA, Ducreux S, Divet A, Bleunven C, Grasso C, et al. Ryanodine receptor 1 mutations, dysregulation of calcium homeostasis and neuromuscular disorders. Neuromuscul Disord $2005 ; 15: 577-87$

16. Pourmand R, Azzarelli B. Adult-onset of nemaline myopathy, associated with cores and abnormal mitochondria. Muscle Nerve 1994;17:1218-20

17. Guis S, Figarella-Branger D, Monnier N, Bendahan D, KozakRibbens G, Mattei JP, et al. Multiminicore disease in a family susceptible to malignant hyperthermia: Histology, in vitro contracture tests and genetic characterization. Arch Neurol 2004;61:106-13.

18. Mathews KD, Moore SA. Multiminicore myopathy, central core disease, malignant hyperthermia susceptibility and RYR1 mutations: One disease with many faces? Arch Neurol 2004;61:27-9.

19. Osada H, Masuda K, Seki K, Sekiya S. Muti-minicore disease with susceptibility to malignant hyperthermia in pregnancy. Gynecol Obstet Invest 2004;58:32-5.

20. Ferreiro A, Monnier N, Romero NB, Leroy JP, Bonnemann C, Haenggeli $\mathrm{CA}$, et al. A recessive form of central core disease, transiently presenting as multi-minicore disease, is associated with a homozygous mutation in the ryanodine receptor type 1 gene. Ann Neurol 2002;51:750-9

21. Sharma MC, Goebel HH. Protein aggregate myopathies. Neurol India $2005 ; 53: 273-9$.

Accepted on 24-10-2006

Source of Support: Nil, Conflict of Interest: None declared. 